\title{
A radioresistant fraction of acute promyelocytic leukemia cells exhibit CD38 cell-surface antigen and mRNA expression
}

\author{
SATORU MONZEN ${ }^{1}$, MITSURU CHIBA ${ }^{2}$, TATSUYA UENO $^{1}$, YUKI MORINO ${ }^{1}$, \\ KENJI TERADA $^{1}$, HIROKI YAMAYA ${ }^{1}$ and YOICHIRO HOSOKAWA ${ }^{1}$ \\ Departments of ${ }^{1}$ Radiation Sciences and ${ }^{2}$ Bioscience and Laboratory Medicine, \\ Hirosaki University Graduate School of Health Sciences, Hirosaki, Aomori 036-8564, Japan
}

Received September 13, 2017; Accepted December 5, 2017

DOI: $10.3892 / \mathrm{ol} .2018 .8099$

\begin{abstract}
In the present study, the cell viability and cluster of differentiation (CD)38 mRNA expression were evaluated in radioresistant (Res)-HL60 acute promyelocytic leukemia (APL) cells. Cell viability in Res-HL60 cells was higher compared with wild-type HL60 cells, but did not differ between high and mid/low CD38 antigen expression groups in Res-HL60 cells. A higher expression of CD38 mRNA in Res-HL60 cells was observed, particularly in the CD $38^{\text {high }}$ cell subpopulation. Furthermore, the expression of CD38 mRNA was upregulated following exposure to $\mathrm{X}$-irradiation. In contrast, the characteristic expression of CD45 and CCAAT/enhancer-binding protein $\alpha$ mRNA were not altered. These results suggest that the accumulation of CD38 protein in radioresistant APL cells, resulting from the constant expression of CD38 mRNA induced by $\mathrm{X}$-irradiation, is a characteristic response of the radioresistant-surviving fraction; however, the accumulation of CD38 did not influence the extent of radioresistant behavior.
\end{abstract}

\section{Introduction}

Leukemic cells and normal hematopoietic tissues are generally more radiosensitive compared with other tissue types (1-3). One method of leukemia treatment, the depletion of leukemia cells by ionizing radiation (IR), exploits this characteristic to restore a normal hematopoietic system $(4,5)$. However, IR may induce the production of radioresistant cells, as radiation induces genetic mutation. The presence of radioresistant cells may result in a poor prognosis for radiation therapy (6). The properties of radioresistant human HL60 acute promyelocytic leukemia (APL) (Res-HL60) cells, a cell line established as an APL model, have been previously reported $(6,7)$. It was

Correspondence to: Dr Satoru Monzen, Department of Radiation Sciences, Hirosaki University Graduate School of Health Sciences, 66-1 Hon-cho, Hirosaki, Aomori 036-8564, Japan

E-mail: monzens@hirosaki-u.ac.jp

Key words: acute promyelocytic leukemia cells, cluster of differentiation 38, radioresistant, mRNA expression observed that high-cluster of differentiation (CD)38-expressing cells were present among the Res-HL60 cells. However, to the best of our knowledge, the properties of the cell population exhibiting high CD38 expression have never been investigated. If the association between CD38 expression and radioresistance can be determined, key factors and countermeasures against the production of radioresistant cells in radiation therapy may be identified.

In the present study, the cell viability and the expression of CD38 mRNA were evaluated in Res-HL60 APL cells.

\section{Materials and methods}

Reagents. Cell culture medium (RPMI-1640) and penicillin/streptomycin were purchased from Thermo Fisher Scientific, Inc. (Waltham, MA, USA). Fetal bovine serum (FBS) was purchased from Japan BioSerum Co., Ltd. (Hiroshima, Japan). Phycoerythrin (PE)-conjugated antihuman CD38 (cat. no. IM1832U) monoclonal antibodies (mAbs) and PE-cyanin-5-forochrome tandem (PC5)-conjugated antihuman CD45 (cat. no. IM2653) mAbs were purchased from Beckman Coulter, Inc. (Brea, CA, USA). The quantification of viable cells was performed using $0.5 \%$ trypan blue liquid solution (Nacalai Tesque, Inc., Kyoto, Japan). In order to analyze gene expression, the Qiagen RNeasy mini kit (Qiagen, Inc., Valencia, CA, USA), the iScript cDNA synthesis kit (Bio-Rad Laboratories, Inc., Hercules, CA, USA) and the iQ SYBR Green Supermix (Bio-Rad Laboratories Inc.) were used.

Irradiation. X-ray irradiation $(150 \mathrm{kVp}, 20 \mathrm{~mA}$, with $0.5 \mathrm{~mm}$ aluminum and $0.3 \mathrm{~mm}$ copper filters) was performed using an X-ray generator (MBR-1520R-3; Hitachi, Ltd., Tokyo, Japan) with a distance of $45 \mathrm{~cm}$ between the focus and the target. The dose was monitored using a thimble ionization chamber placed next to the sample during the irradiation. The dose rate was $\sim 1 \mathrm{~Gy} / \mathrm{min}$, for a total dose of $4 \mathrm{~Gy}$.

Cell preparation and cell culture. Human APL wild-type (Wt) HL60 cells was purchased from RIKEN BioResource Center (Tsukuba, Japan). The Res-HL60 cell line was previously established by subjecting Wt-HL60 cells to 4 Gy X-irradiation/week for 4 weeks $(6,7)$. Wt-HL60 and 
Table I. National Center for Biotechnology Information gene accession numbers and sequences of synthetic human oligonucleotide polymerase chain reaction primers.

\begin{tabular}{lccc}
\hline Primer name & Accession number & \multicolumn{1}{c}{ Sequence } & Size, bp \\
\hline CD38 forward & NM_001775 & 5'-CAGCAACAACCCTGTTTCAGT-3' & 21 \\
CD38 reverse & & 5'-CCATTGAGCATCACATGGAC-3' & 20 \\
CD45 forward & NM_002838 & 5'-CCAATGCAAAACTCAACCCTA-3' & 21 \\
CD45 reverse & & 5'-CCTCTCTCCTGGGACATCTG-3' & 20 \\
CEBPA forward & NM_004364 & 5'-CAGCATTGCCTAGGAACACGAA-3' & 22 \\
CEBPA reverse & & 5'-CACAGAGGCCAGATACAAGTGTTGA-3' & 25 \\
GAPDH forward & NM_002046 & 5'-ACACCCTGGCCTACGCTAAAGAC-3' & 23 \\
GAPDH reverse & & 5'-AGCCCAAGCATCAAAGATGGAG-3' & 22 \\
\hline
\end{tabular}

$\mathrm{CD}$, cluster of differentiation; CEBPA, CCAAT/enhancer-binding protein $\alpha$.

Res-HL60 cells were maintained in RPMI-1640 medium supplemented with $10 \%$ heat-inactivated FBS and $1 \%$ penicillin/streptomycin in a humidified atmosphere at $37^{\circ} \mathrm{C}$ under $5 \% \mathrm{CO}_{2}$.

Flow cytometry. Isolations of $\mathrm{CD} 38^{+} \mathrm{CD} 45^{+}$cells and $\mathrm{CD} 38^{-} \mathrm{CD}^{-} 5^{+}$cells and morphological analysis were performed using fluorescence-activated cell sorting (FACS) with the Aria SORP (BD Biosciences, Franklin Lakes, NJ, USA). The analysis software was used BD FACSDiva v.8.0.1 (BD Biosciences). Samples containing $2 \times 10^{5}$ cells were incubated under saturated concentrations $(500 \mathrm{ng} / \mathrm{ml})$ of the relevant $\mathrm{mAbs}$ for $30 \mathrm{~min}$ at $4^{\circ} \mathrm{C}$, followed by washing and flow cytometric analysis. Isotype-matched $\mathrm{mAbs}$ of anti-CD38 (PE-conjugated anti-mouse IgG1 mAb; cat. no. A07796; $500 \mathrm{ng} / \mathrm{ml}$; Beckman Coulter, Inc.) and anti-CD45 (PC5-conjugated anti-mouse IgG1 mAb; cat. no. A07798; $200 \mathrm{ng} / \mathrm{ml}$; Beckman Coulter, Inc.) were used as negative controls. The threshold values of mean fluorescence intensity for negative-, low-, medium- and high-expression groups for CD38 antigen were defined as $<0.7,0.7-2,2-10$ and $>10$, respectively.

Clonogenic surviving fraction. X-irradiated Wt-HL60 and Res-HL60 cells were cultured using the plasma clot technique, as previously described (8), at $37^{\circ} \mathrm{C}$ in a humidified atmosphere containing $5 \% \mathrm{CO}_{2}$. On the seventh day from the start of irradiation, colonies consisting of $>50$ cells were counted under an inverted optical microscope.

Total RNA extraction and reverse transcription-quantitative polymerase chain reaction $(R T-q P C R)$. The cells were harvested after 2 days, and total RNA was extracted using the RNeasy kit and quantified using a NanoDrop system (Thermo Fisher Scientific, Inc., Wilmington, DE, USA). The total RNA quality was confirmed using a 2100 Bioanalyzer (Agilent Technologies Inc., Santa Clara, CA, USA), and first-strand cDNA were synthesized using the iScript cDNA Synthesis kit according to the manufacturer's protocol. The expression of mRNA was then evaluated using qPCR with the iQ SYBR Green Supermix (Bio-Rad Laboratories, Inc.) and a SmartCycler ${ }^{\circledR}$ II (Takara Bio Inc., Otsu, Japan) with

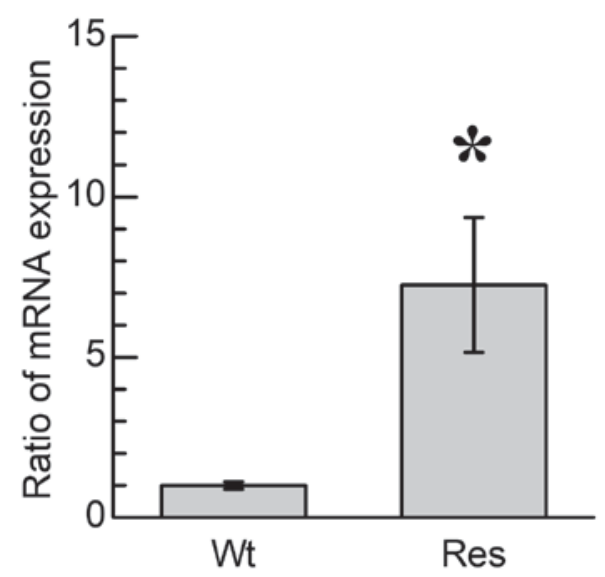

Figure 1. Expression of CD38 mRNA in Res-HL60 cells. mRNA expression was quantified using reverse transcription-quantitative polymerase chain reaction. Values are presented as the means \pm standard error of the mean of 4 separate experiments. ${ }^{*} \mathrm{P}<0.05$ vs. Wt. $\mathrm{CD}$, cluster of differentiation; Res, radioresistant; $\mathrm{Wt}$, wild-type.

the following thermocycler conditions: $95^{\circ} \mathrm{C}$ for $170 \mathrm{sec}$, followed by 40 cycles of $95^{\circ} \mathrm{C}$ for $10 \mathrm{sec}, 65^{\circ} \mathrm{C}$ for $20 \mathrm{sec}$ and $72^{\circ} \mathrm{C}$ for $30 \mathrm{sec}$. Relative levels of $\mathrm{CD} 38, \mathrm{CD} 45$ and CCAAT/enhancer-binding protein $\alpha$ (CEBPA) was determined using the $2^{-\Delta \Delta C a}$ method (9) in cells subjected to 4 Gy X-irradiation after $24 \mathrm{~h}$ of no irradiation, subsequent to normalization with the housekeeping gene GAPDH. The oligonucleotide primer sets used for RT-qPCR were purchased from Hokkaido System Science Co., Ltd. (Sapporo, Japan; Table I).

Statistical analysis. Statistical analysis was performed using OriginLab ${ }^{\circledR}$ Pro Version 9.0 for Windows (OriginLab, Northampton, MA, USA). Two-way factorial analysis of variance followed by Tukey's range post-hoc test was used to assess the statistical significance of differences between the control and experimental groups. Data from two groups were analyzed using an unpaired Student's t-test. Data are presented as the mean \pm standard error of the mean. A total of 4 individual experiments were performed. $\mathrm{P}<0.05$ was considered to indicate a statistically significant difference. 


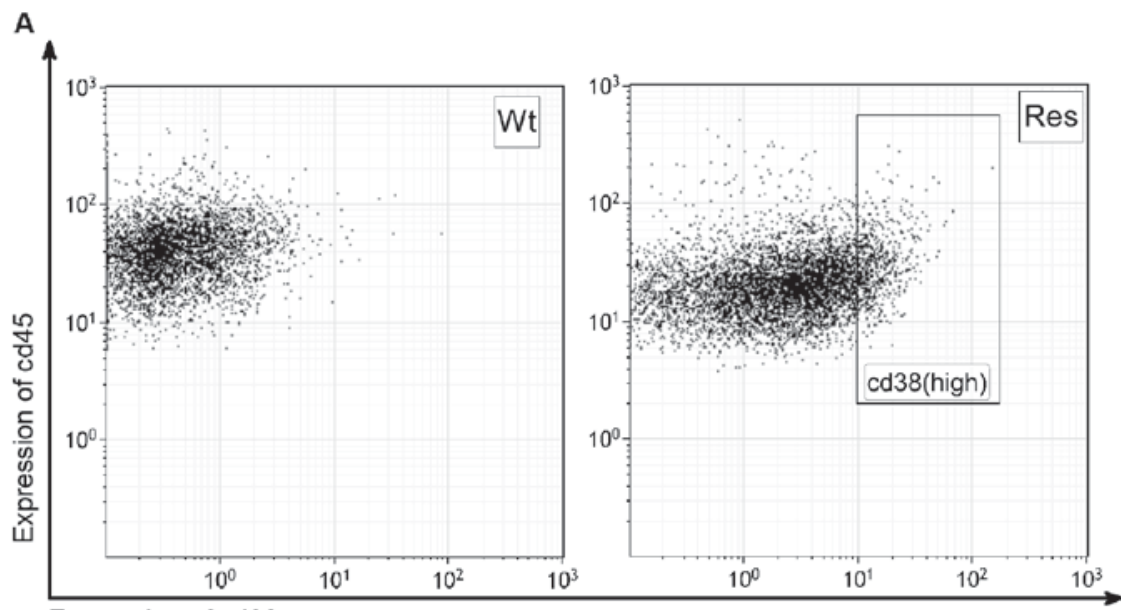

Expression of cd38

B cd38 cell surface antigen

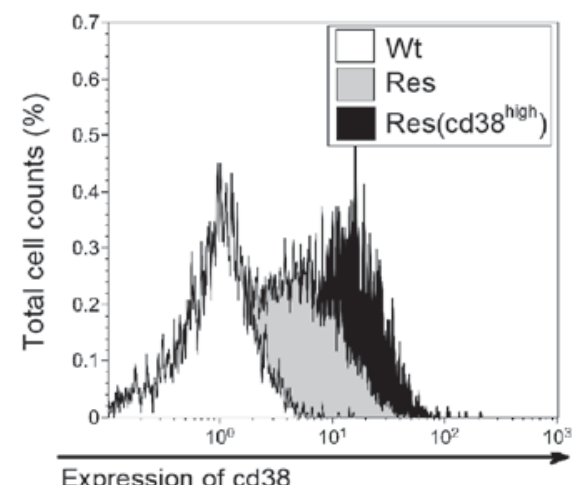

C CD38 mRNA

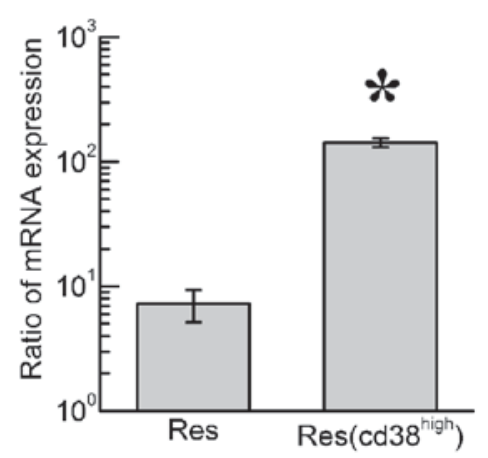

Figure 2. Target cell fraction. (A) The CD $38^{\text {high }} \mathrm{CD} 45^{+}$fraction of Res-HL60 cells, defined as the mean fluorescence intensity of $>10$ for CD38 expression using flow cytometry was isolated by fluorescence-activated cell sorting. The (B) cell-surface antigen and (C) quantified mRNA expression of the isolated CD38 high cells were compared. The $y$-axis in $(B)$ demonstrates the ratio of cell counts in each fluorescence channel. Data are presented as the mean \pm standard error of the mean of 4 separate experiments. "P<0.05 vs. Res. CD, cluster of differentiation; Res, radioresistant; Wt, wild-type.

\section{Results}

Analysis of cell viability in $C D 38^{+}$cells. To clarify the morphological character of Res-HL60 cells, Res-HL60 cells were analyzed using FACS in a previous study; smaller cells with lower granularity were observed in Res-HL60 cells in comparison with Wt-HL60 cells (6). In addition, a significantly higher expression of CD38 protein on the surface of Res-HL60 cells compared with Wt-HL60 cells was observed (6), which concurs with the results of the present study, in which CD38 mRNA expression was significantly increased in the Res-HL60 cells compared with the Wt-HL60 cells $(\mathrm{P}<0.05$; Fig. 1). In previous studies a higher rate of cell proliferation was also observed $(6,7)$.

The CD45 leukocyte-specific antigen was expressed in all Wt-HL60 and Res-HL60 cells. The CD38 ${ }^{+}$cell proportion of Wt-HL60 and Res-HL60 cells was 35.2 and $67.9 \%$ respectively (Fig. 2A and B). On the basis of these data, to confirm whether radiosensitivity is associated with $\mathrm{CD} 38$ expression level, the fraction with the highest $15 \%$ expression of the CD38 antigen in Res-HL60 cells (CD38 high) were isolated using FACS (Fig. 2B). RT-qPCR was used to confirm the high CD38 expression; the CD38 mRNA expression in the Res-HL60-CD38 ${ }^{\text {high }}$ cells was $\sim 37$-fold higher than the non-isolated Res-HL60 cells, representing a significant difference ( $\mathrm{P}<0.05$; Fig. $2 \mathrm{C})$.
A $4.4 \pm 1.3$-fold increase in the number of viable Wt-HL60 cells was observed on day 3 in comparison with day 0 (Fig. 3), whereas the number of viable Res-HL60 cells underwent a $\sim 14.0$-fold increase by day 3 . There was a significant increase in the number of viable cells between Wt and either Res or Res-CD38 ${ }^{\text {high }}$ cells $(\mathrm{P}<0.01$; Fig. 3). However, viability and morphology (data not shown) did not differ between $\mathrm{CD} 38^{+/-}$ and CD38 $8^{\text {high }}$ in the Res-HL60 cells.

Cellular response to exposure to $4 G y X$-irradiation. The survival rates of Res-HL60 cells exposed to 4 Gy X-irradiation were estimated for the CD38-expressing fraction with a clonogenic survival assay, with the aim of determining the association between the expression of the CD38 antigen and the survival rate following radiation exposure. The survival rate for Wt-HL60 cells exposed to 4 Gy X-irradiation was $\sim 2 \%$, which was significantly lower than the surviving fraction of Res-HL60 cells, 10\% ( $\mathrm{P}<0.05$; Fig. 4A). However, the Res-CD38 ${ }^{\text {high }}$ cells exhibited a similar sensitivity to Res-CD38 ${ }^{\text {low/- }}$ cells. In order to investigate the association between the survival rate and the cell cycle distribution, the DNA content of each cell type was analyzed using flow cytometry following the exposure to $4 \mathrm{~Gy} \mathrm{X}$-irradiation, to determine the relative fraction of the cell population in $G_{2} / M$ phase (Fig. 4B). A higher ratio of cells arrested at $\mathrm{G}_{2} / \mathrm{M}$ phase on day 1 in each cell type was observed compared with day 0 , which was 


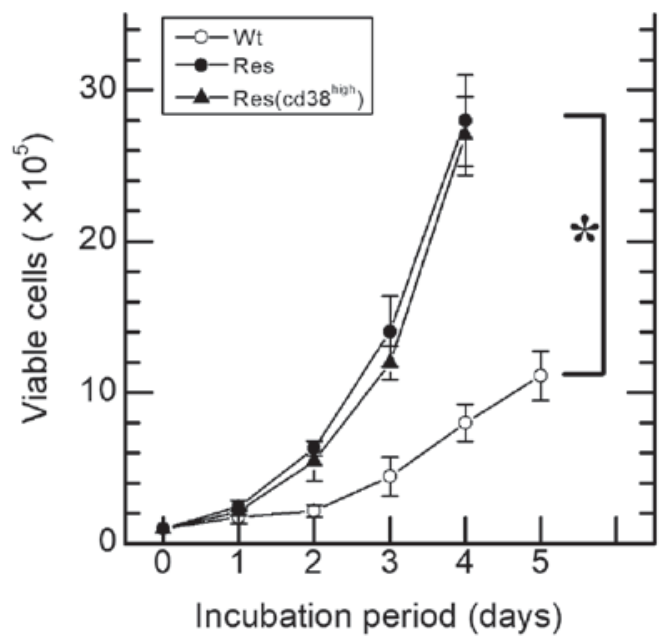

Figure 3. Viable numbers of Wt-HL60 and Res-HL60 cells as assessed by the trypan blue method. The values are mean \pm standard error of the mean of 4 separate experiments. ${ }^{*} \mathrm{P}<0.01$. $\mathrm{CD}$, cluster of differentiation; Res, radioresistant; Wt, wild-type.

relatively decreased on days 2 and 3 (Fig. 4C). The proportion of cells in $\mathrm{G}_{2} / \mathrm{M}$ phase on day 2 was reduced in Res-HL60-CD38 $8^{\text {high }}$ cells in comparison with Wt-HL60-CD38 ${ }^{+/}$cells $(\mathrm{P}<0.01)$ and

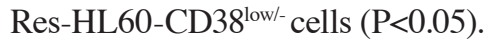

The expression levels of mRNAs associated with cell-surface antigens were evaluated using RT-qPCR (Fig. 5). The expression of the CD38 mRNA in CD38 $8^{\text {low/ }}$ and CD38 $8^{\text {mid/high }}$ Wt-HL60 cells underwent 34.6- and 2.5-fold increases, respectively, in comparison with unexposed Wt-HL60 cells. In $\mathrm{CD} 38^{+/}, \mathrm{CD} 38^{\text {low } /-}$ and $\mathrm{CD} 38^{\mathrm{mid} / \mathrm{high}}$ Res-HL60 cells, 7.2-fold, 3.8-fold and 142.7-fold increases of CD38 mRNA expression, respectively, were observed compared with unexposed Wt-HL60 cells; the difference in the CD38 mRNA expression in Res-HL60-CD38 high cells was particularly remarkable. Additionally, a higher CD45 mRNA expression level in CD38 ${ }^{+/}, \mathrm{CD} 38^{\text {low/ }}$ and $\mathrm{CD} 38^{\mathrm{mid} / \mathrm{high}}$ Res-HL60 cells was observed. Significant differences in the CEBPA mRNA expression, a specific marker of mature white blood cells, were not observed in $\mathrm{CD} 38^{+/}, \mathrm{CD} 38^{\text {low/- }}$ and CD38 ${ }^{\text {mid/high }}$ Res-HL60 cells compared with Wt-HL60 cells.

Following the exposure of 4 Gy X-irradiation, the expression of CD38 mRNA in Res-HL60 cells was significantly increased in comparison with unexposed Wt-HL60 cells, and the CD38 mRNA expression in Res-CD38 ${ }^{\mathrm{mid} / \mathrm{high}}$ cells was 50-fold upregulated (Fig. 5). In contrast, CD45 and CEBPA mRNA expression were similarly expressed in each cell type.

\section{Discussion}

The present study focused on the behavior of Res-HL60 APL cells expressing the CD38 cell-surface antigen. Res-HL60 cells expressing high levels of the CD38 antigen were identified and quantified. Consistent with a previous report (7), viability of Res-HL60 cells was higher compared with Wt-HL60 cells, independent of the expression of the CD38 antigen (Fig. 3). At the gene expression level, a higher expression of CD38 mRNA in Res-HL60 cells was observed, particularly in CD38 $8^{\text {high }}$ cells (Fig. 4). However, no significant increase or suppression of
CEBPA mRNA was observed. These results reveal that the human radioresistant APL cell line previously established by repeated exposure to IR continued to express the CD38 cell-surface antigen and its mRNA; however, this expression was not associated with the capability for cell viability between subpopulations of radioresistant cells.

CD38 is a novel multifunctional ectoenzyme that is widely expressed in cells and tissues, most notably in leukocytes. The synthesis and hydrolysis of cyclic ADP ribose (cADPR) by CD38 is a marker of human leukocyte differentiation (10), and in the context of hematopoietic progenitors, $\mathrm{CD} 34^{+} \mathrm{CD} 38^{-}$ cells are more basal than $\mathrm{CD} 34^{+} \mathrm{CD} 38^{+}$cells (11). $\mathrm{CD} 45$ is a major high-molecular-mass leukocyte cell-surface molecule (12). CEBPA is essential for normal granulopoiesis, and the dominant-negative mutations of the CEBPA gene have been identified in a large proportion of the malignant cells from patients with myeloblastic subtypes of acute myeloid leukemia (13). The results of the present study suggest that the Res-HL60 cells that express the CD38 antigen are at a similar differentiation stage to $\mathrm{CD} 38^{-}$cells, given that the expression of CD45 and CEBPA did not significantly differ between them.

The expression of the CD38 antigen in Res-HL60 cells did not affect the cell viability (Fig. 3) or clonogenic survival (Fig. 4A). However, the CD38 ${ }^{\text {high }}$ cells were less likely to arrest in $\mathrm{G}_{2} / \mathrm{M}$ phase on day 2 after IR exposure (Fig. $4 \mathrm{C}$ ). The accumulation of cells in $\mathrm{G}_{2} / \mathrm{M}$ phase is associated with the repair of cellular damage or the induction of apoptosis (14). It was previously reported that the phosphorylation of $\mathrm{H} 2 \mathrm{~A}$ histone family, member X (H2AX), Checkpoint kinase 1/2 and DNA-dependent protein kinase, catalytic subunit was suppressed in Res-HL60 cells in comparison with Wt-HL60 cells (7). Fernandez-Capetillo et al (15) reported that $\mathrm{G}_{2}$ checkpoint activation was induced by $\mathrm{H} 2 \mathrm{AX}$ and tumor suppressor p53-binding protein 1 phosphorylation, markers of DNA damage. In the present study, Res-HL60 cells expressing higher levels of the CD38 antigen exposed to X-irradiation accumulated in $\mathrm{G}_{2} / \mathrm{M}$ phase on day 2-3 at a lesser rate to other cell groups, suggesting that CD38 expression in Res-HL60 cells influences the $\mathrm{G}_{2} / \mathrm{M}$ checkpoint of the cell cycle directly or indirectly.

CD38/cADPR signaling is an important metabolic pathway for insulin secretion following glucose stimulation to intracellular ATP, and activates a range of cell behaviors $(16,17)$. Thus, we hypothesize that the radiosensitivity in HL60 cells with a higher expression of CD38 is associated with the intracellular energy metabolism, including that of glucose-ATP, and does not induce differentiation. The exposure of Res-HL60 cells to $4 \mathrm{~Gy} \mathrm{X}$-irradiation induced a higher expression of CD38 mRNA compared with non-exposed cells, with notably higher expression in the CD38 $8^{\text {high }}$ cell fraction (Fig. 5). The constant expression of CD38 in Res-HL60 cells may be the result of a mutation inducing CD38 mRNA expression following repeated exposure to ionizing radiation. $\mathrm{X}$-irradiation, which is low-energy transfer radiation, produces reactive oxygen species (ROS), which cause DNA damage (18). Tessitore et al (19) reported that the microRNA associated with DNA repair are necessary for cancer maintenance. Thus, transcription factors directly and/or indirectly regulating the promoter region for CD38 should be identified (20). In a hematological malignancy model, Yalçintepe et al (21) reported that CD38 participates in 

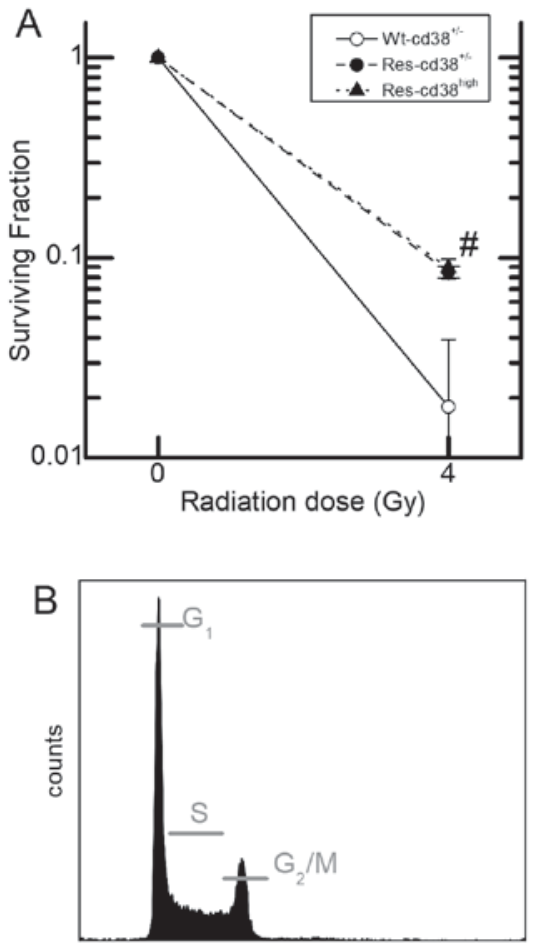

DNA contents $(\log )$

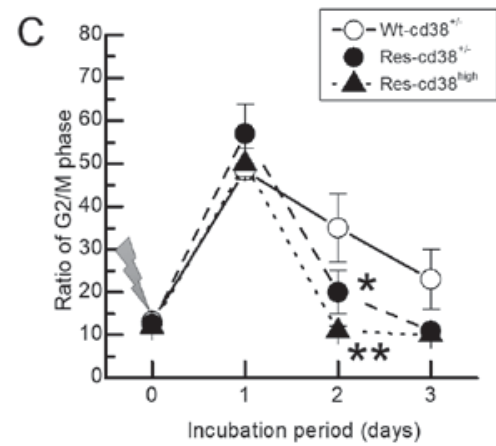

Figure 4. Characteristics of Res-CD38 high cells. (A) Cell survival rates subsequent to 4 Gy X-irradiation, as determined with a clonogenic survival assay. (B) Cell cycle analysis using flow cytometry. (C) Proportion of cells in $\mathrm{G}_{2} / \mathrm{M}$ phase subsequent to exposure to 4 Gy X-irradiation. ${ }^{*} \mathrm{P}<0.05 \mathrm{vs}$. Wt-CD38 ${ }^{+/}$cells . ${ }^{*} \mathrm{P}<0.05,{ }^{* *} \mathrm{P}<0.01$ vs. Wt-CD $38^{+/-}$cells. Res, radioresistant; CD, cluster of differentiation; Wt, wild-type.
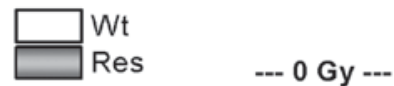

CD38 mRNA

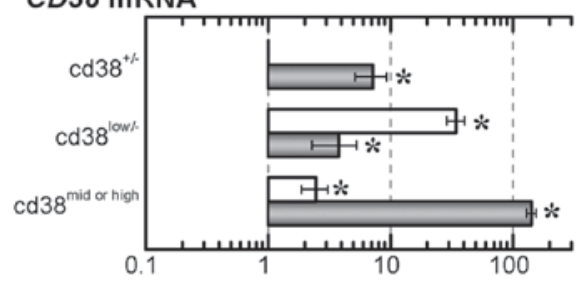

CD45 mRNA

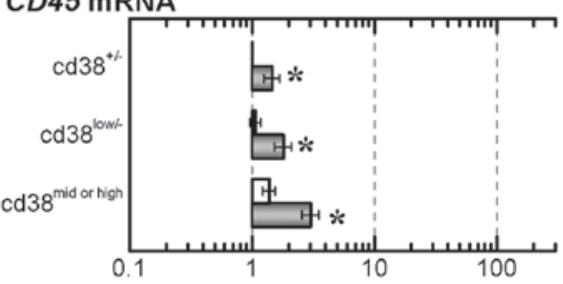

CEBPA MRNA

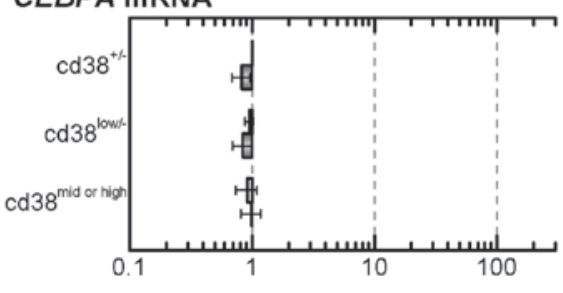

---4 Gy -.-

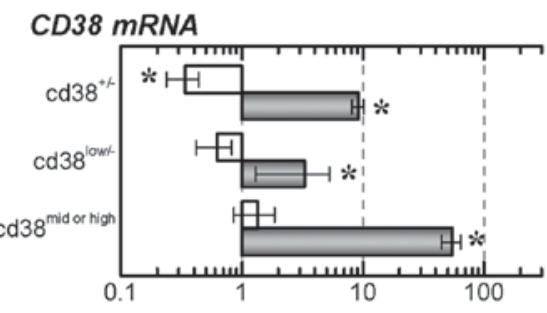

CD45 mRNA

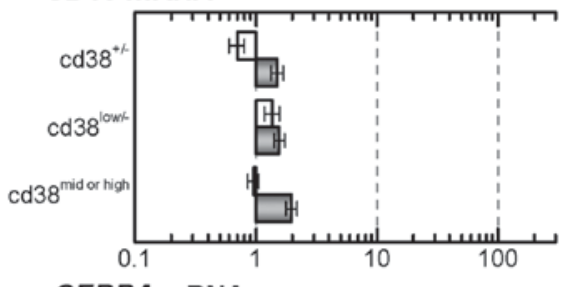

CEBPA mRNA

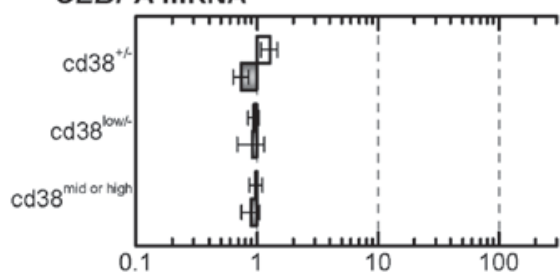

Ratio of mRNA expression (each population/CD $38^{\text {t/ }}$ in Wt-HL60)

Figure 5. Quantitative analysis of CD38, CD45 and CEBPA mRNA expression with or without exposure to 4 Gy X-irradiation at 24 h. Total RNA were isolated from each cell and the expression levels of mRNA were determined using strand-specific reverse transcription-quantitative polymerase chain reaction analysis. The values for mRNAs were normalized to the values of GAPDH mRNA, and the expression of each mRNA was compared as (each population)/(unexposed Wt-HL60 cells). Data are presented as the mean \pm standard error of the mean of 4 separate experiments. ${ }^{*} \mathrm{P}<0.05$ vs. unexposed Wt-HL60-CD38 ${ }^{+/}$cells. CD, cluster of differentiation; CEBPA, CCAAT/enhancer-binding protein $\alpha$; Wt, wild-type; Res, radioresistant. 
the mechanism of drug resistance to chemotherapy. There is a possibility that CD38/cADPR signaling protects from various extracellular stresses to promote radioresistance or anti-cancer drug resistance in leukemia. We hypothesize that CD38 mRNA expression protects the cell from DNA-damaging ROS, as are induced by X-irradiation. However, the present study had limitations, including that the interaction between CD38/cADPR signaling, the CD38 gene network and cell damage by ROS was not evaluated.

Given that the $\mathrm{X}$-irradiation exposure of CD38 $8^{\text {high }}$ Res-HL60 cells did not influence their differentiation level, the suppression of the monocyte lineage induction by Res-HL60 cells, may not directly involve CD45 and CEBPA mRNA (6). There is little information about radioresistant leukemia in clinical literature. The results of the present study may suggest countermeasures against radioresistant leukemia.

In conclusion, the accumulation of the CD38 protein in radioresistant $\mathrm{APL}$, induced by the constant expression of CD38 mRNA following $\mathrm{X}$-irradiation, is a characteristic response of the radioresistant-surviving fraction; however, the accumulated volume of CD38 protein was not observed to influence the extent of radioresistant behavior.

\section{Acknowledgements}

The present study was supported by KAKENHI, Grant-in-Aid for Scientific Research (C; General; grant no., 16K10339 SM) and the Grant for Hirosaki University Young Institutional Research (2013-2014).

\section{References}

1. Ariyoshi K, Takabatake T, Shinagawa M, Kadono K, Daino K, Imaoka T, Kakinuma S, Nishimura M and Shimada Y: Age dependence of hematopoietic progenitor survival and chemokine family gene induction after gamma irradiation in bone marrow tissue in C3H/He mice. Radiat Res 181: 302-13, 2014.

2. Monzen S, Yoshino H, Kasai-Eguchi K and Kashiwakura I: Characteristics of myeloid differentiation and maturation pathway derived from human hematopoietic stem cells exposed to different linear energy transfer radiation types. PLoS One 8: e59385, 2013.

3. Haro KJ, Scott AC and Scheinberg DA: Mechanisms of resistance to high and low linear energy transfer radiation in myeloid leukemia cells. Blood 120: 2087-2097, 2012.

4. de Berranger E, Cousien A, Petit A, Peffault de Latour R, Galambrun C, Bertrand Y, Salmon A, Rialland F, Rohrlich PS, Vannier JP, et al: Impact on long-term OS of conditioning regimen in allogeneic BMT for children with AML in first CR: $\mathrm{TBI}+\mathrm{CY}$ versus BU+CY: A report from the Société Française de Greffe de Moelle et de Thérapie Cellulaire. Bone Marrow Transplant 49: 382-388, 2014.

5. Willemze AJ, Geskus RB, Noordijk EM, Kal HB, Egeler RM and Vossen JM: HLA-identical haematopoietic stem cell transplantation for acute leukemia in children: less relapse with higher biologically effective dose of TBI. Bone Marrow Transplant 40: 319-327, 2007.
6. Monzen S, Takimura K, Kashiwakura I and Hosokawa Y: Acute promyelocytic leukemia mutated to radioresistance suppressed monocyte lineage differentiation by phorbol 12-myristate 13-acetate. Leuk Res 37: 1162-1169, 2013.

7. Hazawa M, Hosokawa Y, Monzen S, Yoshino $H$ and Kashiwakura I: Regulation of DNA damage response and cell cycle in radiation-resistant HL60 myeloid leukemia cells. Oncol Rep 28: 55-61, 2012.

8. Kashiwakura I, Kuwabara M, Inanami O, Murakami M, Hayase Y, Takahashi TA and Takagi Y: Radiation sensitivity of megakaryocyte colony-forming cells in human placental and umbilical cord blood. Radiat Res 153: 144-152, 2000.

9. Yuan JS, Wang D and Stewart CN Jr: Statistical methods for efficiency adjusted real-time PCR quantification. Biotechnol J 3: $112-123,2008$.

10. Takasawa S, Tohgo A, Noguchi N, Koguma T, Nata K, Sugimoto T, Yonekura $\mathrm{H}$ and Okamoto H: Synthesis and hydrolysis of cyclic ADP-ribose by human leukocyte antigen CD38 and inhibition of the hydrolysis by ATP. J Biol Chem 268: 26052-26054, 1993.

11. Petzer AL, Hogge DE, Landsdorp PM, Reid DS and Eaves CJ: Self-renewal of primitive human hematopoietic cells (long-term-culture-initiating cells) in vitro and their expansion in defined medium. Proc Natl Acad Sci USA 93: 1470-1474, 1996.

12. Charbonneau H, Tonks NK, Walsh KA and Fischer EH: The leukocyte common antigen (CD45): A putative receptor-linked protein tyrosine phosphatase. Proc Natl Acad Sci USA 85: 7182-7186, 1988.

13. Pabst T, Mueller BU, Harakawa N, Schoch C, Haferlach T, Behre G, Hiddemann W, Zhang DE and Tenen DG: AML1-ETO downregulates the granulocytic differentiation factor C/EBPalpha in $\mathrm{t}(8 ; 21)$ myeloid leukemia. Nat Med 7: 444-451, 2001.

14. Yamamori T, Yasui H, Yamazumi M, Wada Y, Nakamura Y, Nakamura $\mathrm{H}$ and Inanami O: Ionizing radiation induces mitochondrial reactive oxygen species production accompanied by upregulation of mitochondrial electron transport chain function and mitochondrial content under control of the cell cycle checkpoint. Free Radic Biol Med 53: 260-270, 2012.

15. Fernandez-Capetillo O, Chen HT, Celeste A, Ward I, Romanienko PJ, Morales JC, Naka K, Xia Z, Camerini-Otero RD, Motoyama N, et al: DNA damage-induced G2-M checkpoint activation by histone H2AX and 53BP1. Nat Cell Biol 4: 993-997, 2002.

16. Takasawa S, Nata K, Yonekura $\mathrm{H}$ and Okamoto $\mathrm{H}$ : Cyclic ADP-ribose in insulin secretion from pancreatic beta cells. Science 259: 370-373, 1993.

17. Guedes AG, Rude EP and Kannan MS: Potential role of the CD38/cADPR signaling pathway as an underlying mechanism of the effects of medetomidine on insulin and glucose homeostasis. Vet Anaesth Analg 40: 512-516, 2013.

18. Yamaguchi M and Kashiwakura I: Role of reactive oxygen species in the radiation response of human hematopoietic stem/progenitor cells. PLoS One 8: e70503, 2013.

19. Tessitore A, Cicciarelli G, Del Vecchio F, Gaggiano A, Verzella D, Fischietti M, Vecchiotti D, Capece D, Zazzeroni F and Alesse E: MicroRNAs in the DNA damage/repair network and cancer. Int J Genomics 2014: 820248, 2014.

20. Sun L, Iqbal J, Zaidi S, Zhu LL, Zhang X, Peng Y, Moonga BS and Zaidi M: Structure and functional regulation of the CD38 promoter. Biochem Biophys Res Commun 341: 804-809, 2006.

21. Yalçintepe L, Halis E and Ulku S: Effect of CD38 on the multidrug resistance of human chronic myelogenous leukemia K562 cells to doxorubicin. Oncol Lett 11: 2290-2296, 2016. 